\title{
Telephone based Laçtation Counseling: A Qualitative Study on the Lactation Counselor' s Experience
}

Tahir NM*, Al-Sadat N, Dahlui M

Department of Social \& Preventive Medicine, Faculty of Medicine, University Malaya, Kuala Lumpur, Malaysia

*Corresponding author: Tahir NM, Department of Social \& Preventive Medicine, Faculty of Medicine, University Malaya, Kuala Lumpur, Malaysia, Tel: +6019-6230311; E-mail: drnorzakiah@gmail.com

Received date: July 27, 2015, Accepted date: October 24, 2015, Published date: October 28, 2015

Copyright: (c) 2015 Tahir NM. This is an open-access article distributed under the terms of the Creative Commons Attribution License, which permits unrestricted use, distribution, and reproduction in any medium, provided the original author and source are credited.

\author{
Abstract \\ Background: This qualitative study was undertaken as a follow-up of the results of a randomized controlled trial \\ (RCT) conducted in Kuala Lumpur in 2010.
}

Objective: The main objective of this study was to explore the Lactation Counselors' perspectives regarding counselor-initiated telephone-based lactation counseling service to mothers in Kuala Lumpur. Methods: In-depthinterviews were held with the lactation counselors. The analytical framework was conceptualized using the Grounded Theory method.

Results: The greatest determinant which affected telephone-based lactation counseling was the intention of counselors, followed by external factors such as time constraints, mothers' behaviors and their control in decision making, family influence and cultural differences. Strong motivation is required for the counselors to perform telephone lactation counseling.

Conclusion: The Lactation Counselors in general have appreciated the experiences and benefits gained from the service. However, external factors pose major impact towards the conduct and effectiveness of counseling.

Keywords: Exclusive breastfeeding; Lactation counselors; Telephone counseling; Qualitative study; In-depth interview; Grounded theory

\section{Introduction}

In Malaysia, the exclusive breastfeeding rate in Malaysia remains low despite the implementation of Baby Friendly Hospital Initiative (BFHI) policy since 1993. In a national survey conducted in the year 2006, the overall prevalence of exclusive breastfeeding in Malaysia below 4 months was $19.3 \%(15.5 \%, 23.9 \%)$, while the overall prevalence of exclusive breastfeeding below 6 months was $14.5 \%$ $(11.7 \%, 17.9 \%)[1,2]$. Breastfeeding support and counseling services offered by knowledgeable health professionals can enable mothers and families to overcome breastfeeding obstacles and is often cited in the literature as one of the ways to promote breastfeeding [3-7]. The CDC Guide to Breastfeeding Interventions [8] defines professional support as any "counseling or behavioral interventions to improve breastfeeding outcomes, such as helping with a lactation crisis or working with other health care providers". Counseling helps mothers to be strong enough to deal with pressure, and increasing her selfconfidence and self-esteem [9]. Lester had classified telephone therapy into two basic types, crisis counseling and informational [10], while Rosenfield had categorized telephone services into support, informational, advocacy, helplines, befriending and advice giving [11]. Counseling by telephone has been defined as a service whereby a trained counselor works with a client, or a group of clients, by telephone, to enable the client(s) to explore personal situations, problems or crises in a one-off or in an on-going longer term therapeutic relationship [11]. Telephone counseling has been found to be effective for certain problems, such as smoking cessation [12-15], dietary change [16] and mental health [17], but the research has not been extended to address adequately the effectiveness of telephone counseling alone for breastfeeding practices. The research investigating the effects of telephone counseling for breastfeeding tends to incorporate the intervention as an adjunct with other forms of support [18-21], except for one study [22]. This qualitative study was undertaken as a follow-up of the results of a randomized controlled trial (RCT) conducted in Kuala Lumpur from April 2010 - February 2011 [23]. In the RCT, the intervention group $(n=179)$ received lactation counseling via telephone twice monthly by certified lactation counselors (LCs) in addition to receiving the current conventional care of postnatal breastfeeding support, whilst the control group $(n=178)$ received the current conventional care of postnatal breastfeeding support. A detailed description of the RCT is described elsewhere [23]. This RCT found that at the first month postpartum, there was a 1.8 times higher probability for a mother in the intervention group to exclusively breastfeed her infant (unadjusted OR 1.83, 95\% C.I. 1.05, 3.16). However, there was no difference in the percentage of mothers who exclusively breastfeed their infants between the two groups at the fourth and sixth month postpartum. An analysis of the intervention dosage was carried out and it was noted that the accessibility to counsel the mothers declined gradually and substantially throughout the study. Thus, it is crucial to find the explanations on why the intervention was not successful in 'reaching out' to the mothers at the later stage of postpartum period, despite the feasible of mode of communication. The main objective of this qualitative study was to explore the LCs' perspectives regarding counselor-initiated telephone lactation counseling service to mothers in Kuala Lumpur. Their views 
on the implementation of the service would provide input on the factors which could be modified to make the telephone lactation counseling a more effective approach in promoting exclusive breastfeeding.

\section{Materials and Methods}

\section{Sample recruitment}

Six participants were recruited for the research project from a sample of twelve LCs who had participated in the initial RCT [23]. There was no exclusion criterion, and the inclusion criteria were LCs from a public hospital in Kuala Lumpur who had participated in the intervention study providing telephone-based lactation counseling to mothers. Participants were recruited until theoretical saturation of data was achieved [24], following the principles of Grounded Theory [24-26].

\begin{tabular}{|l|l|l|l|l|}
\hline Participant & Age & Ethnicity & $\begin{array}{l}\text { Years of } \\
\text { experience as a } \\
\text { Nursing Staff }\end{array}$ & $\begin{array}{l}\text { Years of Experience } \\
\text { as } \\
\text { Counselor }\end{array}$ \\
\hline LC1 & 54 & Malay & 29 & 4 \\
\hline LC2 & 45 & Malay & 20 & 7 \\
\hline LC3 & 57 & Indian & 31 & 16 \\
\hline LC4 & 55 & Malay & 31 & 13 \\
\hline LC5 & 49 & Malay & 25 & 7 \\
\hline LC6 & 41 & Malay & 18 & 7 \\
\hline
\end{tabular}

Table 1: Participant's Information.

Data saturation was achieved with 5 participants, but the researcher continued to the sixth participant as she had given the verbal agreement to meet for the IDI. The LCs were informed regarding the purpose of the qualitative study during one of the meetings with the researcher, and were later contacted by telephone and e-mail to fix the interview dates and time. Withdrawal from the IDI could be done at any time during the interview. Written informed consent was obtained from all participants. The first author acted as the Principal Investigator for this qualitative study and the intervention study. Prior to conducting the IDIs the first author was concerned that the LCs would not share information openly with her if they perceived her as one who would judge their views. However, during the course of the IDIs this concern was abated since the counselors shared information openly and voiced their discomforts. Upon reading the transcripts, a colleague of the researcher who did not form part of the intervention team, confirmed that the LCs were more than willing to disclose information freely during these discussions. Information regarding the participants is presented in Table 1.

\section{Data collection and analysis}

This study was conducted in August 2011. The IDIs were conducted by the first author at the time and place convenient to the LCs (i.e. workplace). The interviews were conducted in Malay language (with five LCs) and English (with one LC); each lasted between 30-40 minutes. Each of the interviews was recorded using an audio recorder and was later transcribed verbatim and translated into English by the interviewer. Field notes were also made during each IDI session. To verify the accuracy of the transcription and translation, the interviewer read the transcripts and checked them against the audio recorded interviews. Constant comparative method was applied to look for emerging patterns and themes.

In this study, the qualitative data analysis followed the steps recommended by Charmaz [25]. Each audio-recorded interview was transcribed verbatim and given line numbers and the transcripts were subjected to content analysis. The steps implemented in analyzing qualitative data include: (i) reading and re-reading the transcript to become familiar with the text and begin developing codes; (ii) coding of data by line-by-line coding, and later refined into shorter code phrases; (iii) grouping the phrases into categories (iv) displaying the details of the categories and themes; (v) reducing data to essential points; and (vi) developing an analytical framework by linking the categories and themes.

\section{Materials}

A semi-structured interview design was developed from a list of elicitation questions based on the Integrated Behavioral Model for the IDI [27]. The semi-structured interview questions and an interview guide were prepared in English and later translated to Malay language. Suitability of the questions was discussed with the second author. The IDI questions are listed in Table 2.

\begin{tabular}{|l|l|}
\hline Construct & Elicitation Questions \\
\hline Experiential attitude & $\begin{array}{l}\text { How do you feel about the idea of telephone lactation counseling? What do you like/dislike about telephone lactation counseling? Tell me } \\
\text { about the good or the bad experiences you had when you handle the counseling sessions with the mothers }\end{array}$ \\
\hline Instrumental attitude & $\begin{array}{l}\text { What are the benefits/advantages of you doing the telephone lactation counseling? What are the negative effects/disadvantages of you doing } \\
\text { the telephone lactation counseling? }\end{array}$ \\
\hline Normative influence & What conditions makes you feel unsupported/de-motivated to conduct the counseling? \\
\hline Perceived control & $\begin{array}{l}\text { What makes things easier for you to conduct telephone lactation counseling? What makes it harder for you to conduct telephone lactation } \\
\text { counseling? }\end{array}$ \\
\hline Self-efficacy & $\begin{array}{l}\text { Before you conduct any counseling sessions, how certain are you that you can? Do you feel capable enough to counsel the mothers? What } \\
\text { kinds of things that would help you overcome any barriers in conducting telephone lactation counseling? }\end{array}$ \\
\hline
\end{tabular}

Table 2: Elicitation questions explored during the in-depth interview. 


\section{Results}

The results are a summary of the themes identified from the analysis process with selected quotes included for illustration purposes, representing the LCs perspective on the telephone lactation counseling based on their experiences providing the service.

\section{The Counselors' emotional experience}

During the interviews all of the LCs reported experiencing both positive and negative emotions when counseling mothers. It was noted that their emotions were closely related to the outcome of the mothers' breastfeeding practice, and the mothers' behavioral responses towards the counselors' advice or suggestions. In regards to positive emotional experiences, the interviews revealed that all the LCs experienced happiness when mothers had successfully breastfeed or when mothers were able to overcome their breastfeeding problems with help from the counselors' guidance. They had also reported experiencing hopefulness, felt useful and helpful, felt appreciated or welcomed by mothers, felt the desire to help their clients, and were accepting of their clients despite their client's infant-feeding choices. One of the LCs specifically mentioned that due to the 'seldom occasions' of exclusive breastfeeding among mothers, it brought her pleasure whenever she thought of mothers under her care who had successfully done that [LC3, 57 years old]. They had also enjoyed the interactions with the mothers and in general, had enjoyed giving the counseling to the mothers.

"I asked a mother, and she said that she is still breastfeeding, I felt very happy, it feels like all the effort was worth it, you know, I can't really describe the feeling, but yes, it felt it was all worth it" [LC4, 55].

In regards to negative feelings, they reported feeling sadness, frustration, rejection, helpless, inadequacy, overwhelmed, hopeless, apprehensive, distress, ambivalence, and tiring. Some of the negative emotional experiences felt by the counselors were related to the mothers' responses which the counselors had perceived as them being 'rejected.' To some extent, failure of the mothers to continue breastfeeding had caused the LCs to deduce it as an aftermath of their own failure to help the mothers [LC4, 55]. However, they expressed concern that despite their efforts to offer support during their busy 'core work' schedule, a few of the mothers seemed 'ungrateful' for the 'free help'. The counselors negative experiences caused by technical problems related with calling by telephone (i.e. unanswered calls, unreturned calls, wrong numbers, number no longer in service) were less evident, as they had said that it was expected. Furthermore, some of the counselors had reiterated that the frustrations with the mothers were felt with a more profound sense of emotion, when compared to the technical glitches.

"I do feel frustrated sometimes, with mothers' attitude. They felt that it was okay for them to mix with formula, like it was the right solution for their [breastfeeding] problem, so, I feel frustrated then" [LC2, 45].

\section{Providing the service has its merits}

The LCS acknowledged that provision of the service has its advantages and disadvantages, both to the counselors and the mothers. The LCs had agreed that the most beneficial effect from providing the service was that more mothers would get help with breastfeeding. They had also stated that besides the mothers, the LCs had also benefited from the sessions, citing that they had noticed that their counseling skills had improved, they became better negotiators, and they became more aware with their own ability to help. The counselors has also adapted the previously learned counseling skills for this service, as they claimed the bulk of the training focused on face-to-face counseling with mothers [9].

The LCs were not very explicit about the disadvantages of the service when probed openly about this topic. They had iterated that every support towards breastfeeding is something that is beneficial. However, when asked directly how the conduct of this service had affected their core job or their time, all of them agreed to some extent that the service had cost them their time. They had implied that their utmost priority was still their core job as appointed by the head of department, thus making them resort to doing the counseling during their time-off, on weekends or stayed back after their working hours. Thus it was apparent that the counselors' insights regarding disadvantages were directed more towards the lack of time for themselves.

\section{Perceived control}

The interviews revealed that there were several factors which had facilitated the LCs during the intervention study period. The LCs' owns passion to help breastfeeding mothers was a profound 'internal' factor which has helped them to pursue with the intervention. Their determination to convince the mothers and the commitment to provide the support and guidance for breastfeeding mothers were the most important motivation.

The mothers' inquisitive attitude towards breastfeeding was the most discussed 'external' facilitating factor to the LCs in providing the service, and the effect of this was it developed into a better and positive environment for counseling.

"When I had a mother who is interested to breastfeed, it is easier to counsel her, she usually asks more questions...I feel at ease because I know she will somehow practice what I teach her, and I know what she wants from me" [LC6, 41].

All of the LCs had agreed that the provision of a guideline booklet has helped them during the counseling session. In fact, it was this factor that made a difference from a face-to-face counseling, as there was no way during face-to-face counseling that they could use any guideline book to avoid being seen as 'incompetent'.

The external barriers felt by the counselors were apparently causing more restrictions towards provision of good support to the mothers. The counselors felt that they were somehow 'restricted' to conduct counseling sessions during their working time. The counselors' actions were deeply suppressed by some mothers who seemed unbothered to seek help. They expressed disbelief with some of the mothers' attitude, who were quite difficult in accepting their opinions regarding breastfeeding. These attitudes may have led the counselors to stereotype the mothers as being the 'difficult ones', hence the rigor of approach to these mothers may dwindled or increased according to the counselors' motivation level. Although the counselors have tried to their best capacity to guide the mothers, the ultimate decision-making power still remains in the mother's hands. This fact was agreed upon by all of the LCs, with one of the counselors who consciously said that breastfeeding is a voluntary act and it could not be forced upon mothers [LC3, 57]. Other barriers felt by the LCs were the influence posed by the mothers' family members, particularly from their own mothers or mother-in-laws. They speculated that the influence by these people greatly affect the course of breastfeeding in any mothers as the 
expectance to 'obey' the elderly is still deeply rooted in the local culture.

"At the end of the day, the fact is, it still depends on the mothers. We helped them all we could, but the choice is still theirs. That is the reality" [LC4, 55].

Cultural differences were also seen as a barrier in certain situation, not only confined to the practices of breastfeeding but also include the language barriers, and preference to talk to somebody from the same race. In this current study, it was noted that the use of cultural stereotypes had been applied by the LCs. Problematic communication experiences with a few individuals of different ethnicity in the past may have strengthened the cultural stereotyping towards the whole ethnicity group. Communication barriers which were related to cultural differences have an influence to the delivery of health services in some extent [28]. Depersonalizing and stereotyping the mothers according to their ethnicity may have influenced the equity of service provision, in this case, the telephone lactation counseling. It raises questions whether these acts could be seen as being racially-biased, however, as mentioned by one of the counselors that preference to the same ethnicity is unavoidable in any multi-ethnic society $(L C 3,57)$ in addressing certain personal issues such as breast feeding. 'Internal' barriers expressed by the counselors revolved around their limited time, and limited energy to provide a more in-depth counseling after a busy day of work. Some of the counselors had internally believed that telephone counseling is inferior to face-to-face, but some of them felt there was indifference between the two methods.

\section{Mothers' influence in service provision}

The LCs had voiced out their concern on the mothers' influence towards the success of service provision. The mothers' positive responses towards the LCs' advice, their co-operation to be guided through the session, their co-operation to answer and receive the telephone calls, gave a profound encouraging effect towards the motivation to perform within the counselor. Exhibition of behaviours of trust towards the counselors had a gratifying effect on their confidence level and feeling of self-competence. The LCs were also affected by the negative influence projected by the mothers. They found it especially disturbing when dealing with mothers who have their own concept of infant feeding, be it the mothers' own ways of breastfeeding, the appropriate time to wean, or their indifference towards formula feeding. One of the counselors was taken aback when a mother had somehow 'reminded' her that she has had more experience than the counselor, and that her children were doing fine despite not complying to what the 'hospital' had advised [LC2, 45]. Mothers who posed these negative feelings do affect the LCs emotionally, up to the point that they felt uneasiness before contacting the mother again, felt less enjoyment conducting the counseling and had foreboded the outcomes of counseling [LC5, 49].

\section{Compatibility to provide service}

The LCs has had to manage the counseling sessions while doing their core work in the hospital. The lactation counselors had exhibited self-efficacy, had adequate knowledge and skills to counsel lactating mothers and had to time-manage themselves in between doing the core work and counseling. The counselors expressed that by joining this service group, they realized that they had to be seen and heard by the mothers as 'the person' to refer pertaining to breastfeeding. Thus, they had felt the need to prove their competence; to a certain higher degree expected when compared to the mothers they had managed in the wards. This occurred especially when the counselors worked with mothers who were more educated, or had access to breastfeeding education through media and internet. Although they claimed to be capable of conducting counseling on usual basis, they had felt the need to tailor to the mothers' need far greater during telephone counseling. The traditional autonomy of counselors during telephone counseling is non-existential, and the counselors had to adapt to that situation as well.

Majority of the counselors had implied that the way of approaching the mothers as the most important aspect to conduct any counseling. Besides talking in a calming manner, they also had to project empathy towards the mothers. Empathetic counseling were used as much as possible, with many of them used coaxing methods when dealing with mothers who seemed to have given up trying to breastfeed, or being persuasive when mothers were undecided during the counseling session. However, the LCs had also shared that there were times when they had a 'hurried counseling' session. Hurried counseling occurred when the counselors were pressed for time, or when the mother requested for the counseling to end before it's due. Counselors had also maneuvered the handling of certain situations to gain more trust from the mother and be seen as competent.

Time management was also another important aspect in providing the service. Due to the lack of suitable time during their working hours, the LCs conducted the counseling during their weekends or during their time-off from work. Besides juggling to find the time to call the mothers, they also had to tailor to individual mother's suitable time. This was to ensure that the patient is comfortable and ready enough to be in part of and engage in the counseling. Several of the counselors had improvised on the methods of communication, by using the short message service (sms) to fix an appointment date and time.

They had also had to handle difficult situations, in cases where there is a language barrier, or handling different types of personalities among the mothers. Handling the different types of mothers' responses and behavior's towards breastfeeding was accepted by the counselors as the part and parcel of counseling. Two of the lactation counselors however, expressed the difficulty of passing certain types of information related to breastfeeding over the telephone [LC4, 55; LC3, 57].

\section{Features of telephone lactation counseling}

This theme emerged as the counselors explained why they had failed to reach to some mothers. They explained that while telephone counseling does feature certain highlights better than face-to-face counseling, it also has its downsides. The counselors had given an appreciation to telephone counseling, as they recognized it as an alternative to the current breastfeeding telephone helplines. Telephone counseling provided anonymity to both sides; it helps mothers overcome their shyness, and it conceals any insecurity feelings from both parties. The LCs also touted that this form of intervention was probably a good tool for an early detection for mothers at risk to stop breastfeeding, thus an early intervention in the form of vigorous support could be provided for this group of mothers.

Despite the ease and comfort of using telephone as a mode of communication, some of the counselors felt that this method was not as superior as the conventional face-to-face counseling. They believed that it was important to have direct contact with the mother, as certain issues or breastfeeding problems would be better explained with 
practical hands-on session. Mothers would also hold the autonomy during any telephone counseling, as they may choose either to respond or ignore the telephone calls. The counselors also expressed the technical problems faced while using the telephone as the mode of communication. It was recognized as the main technical hindrance to provide counseling. Among the technical problems were (in accordance to the number of times they were repeated by counselors): mothers' changed their mobile telephone number, wrong telephone number, number no longer in service, the husband held the number, and the mother was not at their own home during confinement (for mothers who only has direct land-lines).

\section{Discussion}

The themes identified in this study could be presented in an analytical framework (Figure 1) based on the Integrated Behavioral Model [29]. In this model, the most important determinant is the intention to perform the behavior. A person is unlikely to perform the behavior should there be any lacking in motivation to do so. Besides having a strong behavioral intention, a person needs to have the knowledge and skills to perform the behavior. There should be no or few environmental constraints that make behavioral performance very difficult or impossible to conduct, and the behavior should be salient to the person. With experience, performing the behavior becomes habitual, thus intention becomes less important in determining behavioral performance for that individual [30]. Thus, it could be postulated that successful telephone lactation counseling is most likely to occur if (1) the LC has a strong intention to perform it and the knowledge and skill to do so, (2) there is no serious external constraints preventing performance, (3) telephone lactation counseling is salient, and (4) the LC has performed counseling's previously. However, from this qualitative study, it was found that the greatest determinant which affected the provision of telephone-based lactation counseling was the intention of Lactation Counselors, followed by external constraints. Considering that the external constraints could not be controlled by the LCs, strong intentions and motivation are required for the counselors to perform telephone lactation counseling. Other determinants such as demonstration of counseling skills and ample knowledge on breastfeeding among the LCs, salience of the intervention and the habits of conducting counseling were deemed sufficient to influence the conduct of telephone lactation counseling.

Rosenfield has stated some of the advantages which telephone counseling can bring compared to face-to-face counseling [31]. It was noted however, that the tradition that counseling takes place on the counselor's terms is challenged. The counselors could only work on what the mother had chosen to tell and what the counselor can hear in the background [31]. Telephone-based lactation counseling is lacking in the face-to-face interaction, thus it became 'conversational' and lack in immediacy of contact. This may have built an invisible divider between the mother and the counselor. Counselors in telephone-based services may be required to project immediacy exclusively through verbal expressions such as addressing by the mothers' name, engaging in humor, giving praises and encouragements. However, demonstration of verbal expressions of immediacy demands highly skilled and experienced counselors in the specific area of interest to project an effect of warmth and likeability within their telephone communication. Based on the social presence theory [32], lactation counselors need to demonstrate a higher level of social presence in an online environment such as telephone counseling (i.e. attributes that are more sociable, more personal, more sensitive, and warmer), so that they will be perceived by mothers as a "real person".

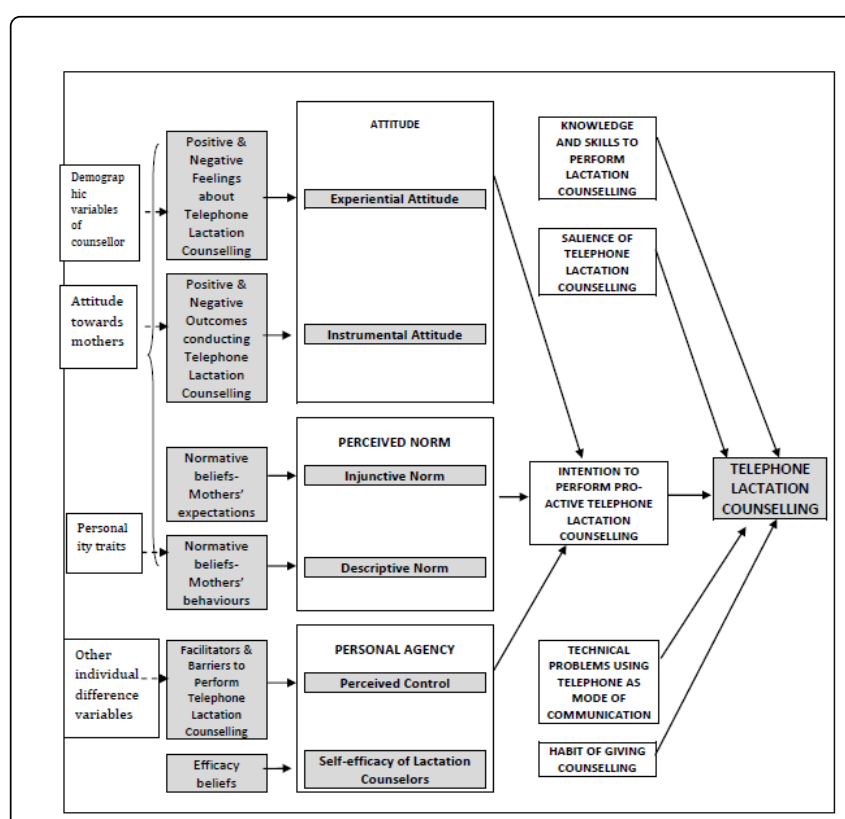

Figure 1: Analytical Framework on the Lactation Counselors' perspectives of Performing Telephone Lactation Counseling, adapted from Integrated Behavior Model.

Good communication between mothers and their counselors can influence information exchange, satisfaction with care, and adherence to the advice given. Communication that is centered more on mothers and their concerns may enhance information gathering and relationship building. Another way in which these counselors can bridge communication gaps with their breastfeeding mothers is through the use of motivational interviewing, a patient-centered approach to counseling and health promotion that has been studied extensively in promoting preventive health behaviors such as smoking cessation [32]. Our findings suggest that there is a need to study the application of motivational interviewing and other patient-centered communication approaches in breastfeeding support.

Counseling via telephone is also affected by the client's control. However good a counselor may be, the ability to conduct the consultation still depends on the client's own perception on the help they needed and their acceptance to receive the help. It was also important to take into account that traditionally, counseling is a twoperson activity which arises when one person (the client) seeks help of another (the counselor) [33]. Hence, telephone lactation counseling might produce better effects when mothers are the ones who seek the lactation counselors rather than vice versa.

The findings in this qualitative study pose several implications, particularly for the public health policy planners and lactation counselors. If this intervention were to be implemented, several improvements on the intervention are necessary, particularly on training the LCs on matters related to telephone counseling. A better system of tele-communication has to be in place before the service is offered. A needs-based study exploring the mothers' expectations of the LCs should be conducted among the multi-ethnicity groups. It is 
best if the LCs and the mothers were introduced to each other before the mother is discharged home to foster the engagement towards the counseling sessions. However, more emphasis is needed for antenatal lactation education, as this would allow the mothers to be more prepared to embrace breastfeeding and knowledgeable enough to seek help when the need arises. In-corporation of the family members during the antenatal lactation education is also essential as they pose the greatest influence on breastfeeding during the postpartum period.

This study has several limitations. The researcher's own belief, feelings, values and viewpoints may have influenced the interpretation of the participants' narratives. However, this limitation is reduced as the reflections resulted from the interaction with the participants long before the conduct of this qualitative study, the preparation of the interviews, literature reviewed as well as the observations made during the interview. Another limitation is the generalizability of the findings is limited to the specific group of persons, who had provided similar counseling services. Although an experimental quantitative study may give different information, it will not be able to access the personal views and descriptions provided by this research. The descriptions presented in this study are valuable in understanding the LCs' experiences of providing telephone lactation counseling to the mothers who had returned home. It is hoped that the themes extracted from these voices will be an impetus to further research and give valuable insights for the policy makers and planners.

\section{Conclusion}

The Lactation Counselors has provided their views regarding the provision of telephone lactation counseling. In general, they have appreciated the experiences and benefits gained from the service. Their passion, commitment, and compatibility to help breastfeeding mothers were undeniable. Several determinants which influence the service include strong intentions and motivation among the counselors, ample knowledge on breastfeeding, and demonstration of counseling skills and salience of the intervention. However, external factors such as time constraints, mothers' behavior's and their control in decision making, family influence and cultural differences pose major impact towards the conduct of counseling. We will need to improvise on the intervention and counteract the external constraints if telephone-based lactation counseling services is to be introduced in Malaysia.

\section{Acknowledgements}

The authors would like to express their deepest gratitude to the Institute of Research Management and Consultancy, University of Malaya for financial funding, the Head of Obstetrics and Gynecology Department, MHKL for his support on this study and most of all to the Lactation Counselors from MHKL who had participated in this research.

\section{References}

1. Mohd Tahir N, Al-Sadat N (2013) Does telephone lactation counseling improve breastfeeding practices? A randomised controlled trial. Int J Nurs Stud 50: 16-25.

2. Fatimah S, Siti Saadiah H, Tahir A, Imam Hussain M, Ahmad Faudzi Y (2010) Breastfeeding in Malaysia: Results of the Third National Health and Morbidity Survey ( NHMS III ) 2006. J Nutr 16: 195-206.

3. Britton C, McCormick FM, Renfrew MJ, Wade A, King SE (2007) Support for breastfeeding mothers. Cochrane Database Syst Rev 1-78.
4. De Oliveira MI, Camacho LA, Tedstone AE (2001) Extending Breastfeeding Duration Through Primary Care: A Systematic Review of Prenatal and Postnatal Interventions. J Hum Lact 17: 326-343.

5. Chung M, Ip S, Yu W, Raman G, Trikalinos T, et al. (2008) Interventions in Primary Care to Promote Breastfeeding: A Systematic Review. Agency Healthc Res Qual 66.

6. Hannula L, Kaunonen M, Tarkka MT (2008) A systematic review of professional support interventions for breastfeeding. J Clin Nurs 17: $1132-43$.

7. Wambach KA, Aaronson L, Breedlove G, Domian EW, Rojjanasrirat W (2011) A randomized controlled trial of breastfeeding support and education for adolescent mothers. West J Nurs Res 33: 486-505.

8. Shealy KR, Li R, Benton-Davis S, Grummer-Strawn LM (2005) The CDC Guide to Breastfeeding Interventions. Public Health Publicaiton, Atlanta.

9. WHO/ UNICEF (1993) Breastfeeding counseling: A training course. World Health Oeganization, Geneva.

10. Lester D (1974) The unique qualities of telephone therapy. Psychotherapy 11: $219-221$.

11. Rosenfield M (1996) Counseling by Telephone. Sage Publications, London 6.

12. Zhu SH, Tedeschi G, Anderson C, Pierce J (1996) Telephone counseling for smoking cessation: what's in a call. J Couns Dev 75: 93-102.

13. Rabius V, McAlister AL, Geiger A, Huang P, Todd R (2004) Telephone counseling increases cessation rates among young adult smokers. Heal Psychol 23: 539-541.

14. Peterson AV, Kealey KA, Mann SL, Marek PM, Ludman EJ, et al. (2009) Group-randomized trial of a proactive, personalized telephone counseling intervention for adolescent smoking cessation. J Natl Cancer Inst. Oxford University Press 101: 1378-1392.

15. Kealey KA, Ludman EJ, Marek PM, Mann SL, Bricker JB, et al. (2009) Design and Implementation of an Effective Telephone Counseling Intervention for Adolescent Smoking Cessation. J Natl Cancer Inst 101: 1393-1405.

16. Eakin E, Reeves M, Lawler S, Graves N, Oldenburg B, et al. (2009) Telephone counseling for physical activity and diet in primary care patients. American Journal of Preventive Medicine 36: 142-149.

17. Reese RJ, Conoley CW, Brossart DF (2002) Effectiveness of telephone counseling: A field-based investigation. J Couns Psychol 49: 233-242.

18. Pugh LC, Serwint JR, Frick KD, Nanda JP, Sharps PW, et al. (2010) A Randomized Controlled Community-Based Trial to Improve Breastfeeding Rates Among Urban Low-Income Mothers. Acad Pediatr 10: 14-20.

19. Bonuck KA, Trombley M, Freeman K, McKee D (2005) Randomized, controlled trial of a prenatal and postnatal lactation consultant intervention on duration and intensity of breastfeeding up to 12 months. Pediatrics 116: 1413-1426.

20. McDonald SJ, Henderson JJ, Faulkner S, Evans SF, Hagan R (2010) Effect of an extended midwifery postnatal support programme on the duration of breast feeding: a randomised controlled trial. Midwifery, Elsevier 26: 88-100.

21. Frank D, Wirtz S, Sorenson J, Heeren T (1987) Commercial discharge packs and breast-feeding counseling: effects on infant-feeding practices in a randomized trial. Pediatrics 80: 845-854.

22. Fallon AB, Hegney D, O’Brien M, Brodribb W, Crepinsek M, et al. (2005) An evaluation of a telephone-based postnatal support intervention for infant feeding in a regional Australian city. Birth 32: 291-298.

23. Egan TM (2002) Grounded Theory Research and Theory Building. Adv Dev Hum Resour 4: 277-295.

24. Charmaz K (1983) The grounded theory method: An explication and interpretation. Theory and Evidence in Field Research 109-126.

25. Glaser BG (2002) Conceptualization: On Theory and Theorizing Using Grounded Theory. Int J Qual Methods 1: 1-31.

26. Montaño DE, Kasprzyk D (2008) Theory of Reasoned Action, Theory of Planned Behavior, and the Integrated Behavior Model-Health Behavior 
Citation: Tahir NM, Al-Sadat N, Dahlui M (2015) Telephone based Lactation Counseling: A Qualitative Study on the Lactation Counselor's Experience. Arts Social Sci J 6: 125. doi:10.4172/2151-6200.1000125

Page 7 of 7

and Health Education: Theory, Research and Practice. John Wiley and Sons.

27. Robinson M (2002) Communication and Health in a Multi-ethnic society. The Policy Press.

28. Racine EF, Frick K, Guthrie JF, Strobino D (2009) Individual net-benefit maximization: A model for understanding breastfeeding cessation among low-income women. Matern Child Health J 13: 241-249.

29. Pechlivani F, Vassilakou T, Sarafidou J, Zachou T, Anastasiou CA et al (2005) Prevalence and determinants of exclusive breastfeeding during hospital stay in the area of Athens, Greece. Acta Paediatr 94: 928-934.
30. Rosenfield M (1997) Counseling by Telephone. Sage Publications, London 101

31. Short J, Williams E, Christie B (1976) The Social Psychology of Telecommunication. John Wiley, London, England.

32. Britt E, Hudson SM, Blampied NM (2004) Motivational interviewing in health settings: A review. Patient Educ Couns 53: 147-55.

33. McLeod J (2009) Defining Counseling: An Introduction to Counseling (4thedn). Open University Press, Berkshire, England pp: 4-9. 